\title{
Noninvasive vaccination as a casus belli to redeem vaccine value in the face of anti-vaccine movements
}

\author{
De-chu C. Tang* \\ Department of Infectious Diseases, Southwest Hospital, Third Military Medical University (Army Medical University), Chongqing, China
}

\begin{abstract}
Formidable anti-vaccine movements have been growing as a menace to disrupt beneficial vaccine programs. Although the vaccination-associated adverse effects commonly perceived by vaccine resisters usually represent over-reactions to rare manifestations, converging evidence shows that vaccination-associated health threats could be pervasive when systemic inflammation is considered as a side effect that oozes over time. An anti-vaccine movement thus may not be so unfounded even though the myriad cascades triggered by systemic inflammation have not been brought to a clear focus during any anti-vaccine campaign. Since both pro- and antivaccine groups are acting on the same primal impulse - "keep people healthy," reconciliation between the two warring factions should be achievable on a palatable trend that fosters the development of noninvasive vaccines which tend to induce local and transient inflammation along the interface with diminished potential to percolate through internal organs.
\end{abstract}

\begin{abstract}
Anti-vaccine movements fueled by vaccines' incertitude
Vaccination is widely heralded as a medical paradigm credited with mitigation of many vaccination-preventable diseases through massimmunization programs. However, its success has also precipitated an active opposition. The genesis of the anti-vaccine movement surge could be traced back to the anti-vaccine sentiment catalyzed by the Britain's Compulsory Vaccination Act of 1853, which mandated the vaccination of all infants [1]. The controversial pertussis and hepatitis $B$ virus (HBV) vaccines in conjunction with the apocryphal link between vaccination and autism not only re-catalyzed a groundswell of antivaccine activism but catapulted it into a phase of erudite opposition [2].
\end{abstract}

Anti-vaccine groups are formed mostly by affluent "knowledge seekers" who claim the right to make "informed choices" about vaccination [2-4]. Today's vaccines largely represent a double-edged sword to vaccine resisters even though they are agnostic about what causes vaccines' side effects. Regardless of their creeds, the incipient anti-vaccine movements have been implicated in low vaccine coverages in conjunction with hazardous outbreaks of preventable diseases [5].

The grand success of vaccination programs is undeniable, and no anti-vaccine groups in the modern era have advocated a divorce by forbidding vaccines altogether in the medical arsenal. The schism between vaccine supporters and resisters can be attributed to the scope of restricted use of vaccines. Vaccine supporters' zeitgeist is based on the belief that vaccines' risks are minuscule with their core health benefits in vanquishing diseases far eclipse their risks, whereas vaccine resisters fear the brunt of vaccination due to vaccines' incertitude and their arcane mechanisms of action. Overall, the bifurcated stances are not as mutually exclusive from an ethical perspective.

Vaccine supporters often impugn vaccine resisters for avoiding vaccination against communicable diseases on the premise that individuals opting out of immunization may jeopardize "herd immunity," which ensures community health in present-day mobile society. Vaccine resisters are ceaselessly discredited as paranoids who are medically wrong by inveighing against vaccination as an unsafe regimen upon ostensible evidence. What is not controversial is the truism: Data have primacy over perception. At this time, emerging evidence begins to reveal that vaccines' risks may not be so minuscule. Assertions of safety by vaccinemakers are invariably based on incomprehensive trial designs with long-term effects under-targeted. Notably, it is extremely difficult, expensive, and time-consuming to seek proof of causation for chronic diseases with adverse effects accruing over many years. Vaccines' chronic impacts on health over a lifetime have been inadequately investigated and poorly understood.

Vaccines' side effects are invariably complex, often stealthy, and inherently multi-dimensional as contextual medical puzzles. Studies on vaccination-related adverse effects often have a limited scope, differ in approach, and contradict one another [6]. To muster the resolve for arresting these festering hazards, their true scope has to be brought to a clear focus. As shown in Table 1, almost any vaccine can induce anaphylaxis that occurs 1.3 times per million vaccinations [7]. Brachial neuritis afflicts up to 10 of every million tetanus vaccinees [7]. The Centers for Disease Control and Prevention (CDC) in the U.S. recommended 26 vaccine doses for infants in 2007 with clinical implications suggesting deleterious impacts on infants' health due to uncharacterized interference among unrelated vaccines after consecutive cycles of intensive immunization [8]. All measlescontaining vaccines are associated with several types of adverse events, including seizure, fever, and immune thrombocytopenia purpura [9].

Correspondence to: De-chu C. Tang, Department of Infectious Diseases, Southwest Hospital, Third Military Medical University (Army Medical University), Chongqing, China, dechutang@163.com

Key words: vaccine safety; anti-vaccine movement; injectable vaccine; noninvasive vaccine; inflammation

Received: August 12, 2017; Accepted: September 13, 2017; Published: September 15, 2017 
Table 1. Adverse effects associated with injectable vaccines

\begin{tabular}{|c|c|c|}
\hline Injectable vaccines & Adverse effects & $\begin{array}{l}\text { Elevation of inflammatory } \\
\text { markers }\end{array}$ \\
\hline All injectable vaccines & Pain; fear; inflammation; anaphylaxis; bursitis and shoulder injury & \\
\hline Comorbid vaccines & Correlation between infant mortality/hospitalization rates and the number of injected doses of unrelated vaccines & \\
\hline $\begin{array}{l}\text { Diphtheria-pertussis- } \\
\text { tetanus vaccine }\end{array}$ & Fever; brachial neuritis & \\
\hline Influenza vaccines & $\begin{array}{l}\text { Platelet activation; systemic inflammation; cardiac autonomic dysfunction; Guillain-Barré syndrome; narcolepsy; } \\
\text { deterioration of endothelial function; abnormal arterial function; LDL oxidation; increase in cardiovascular risk; IgE } \\
\text { sensitization; hamper the development of cross-reactive immunity against influenza viruses of other subtypes; exacerbate } \\
\text { influenza virus infection }\end{array}$ & CRP; TNF- $\alpha$ \\
\hline Measles vaccine & Fever; seizure; immune thrombocytopenia purpura; exacerbation of measles virus infection & \\
\hline Dengue vaccine & Exacerbation of infection by another dengue virus strain; headache; fatigue; fever & \\
\hline Anthrax vaccine & Flu-like symptoms & \\
\hline Papillomavirus vaccine & Myalgia; headache & \\
\hline Salmonella typhi vaccine & Systemic inflammation; vasodilation impairment; disruption of sleep cycle & CRP; TNF- $\alpha$; IL-6; granulocytes \\
\hline HBV vaccine & Systemic inflammation; uveitis & CRP \\
\hline $\begin{array}{l}\text { Pneumococcal } \\
\text { polysaccharide vaccine }\end{array}$ & Cellulitis-like reaction; fever; leukocytosis & \\
\hline $\begin{array}{l}\text { Alum-adjuvanted } \\
\text { vaccines }\end{array}$ & Macrophagic myofasciitis lesions; chronic inflammation; fever; myalgia; lethargy; predisposition of a lymphoma state & \\
\hline
\end{tabular}

Current split formulation for the seasonal influenza vaccines in an intramuscular (i.m.) regimen tends to induce immunoglobulin (Ig) E sensitization in children [10]. Annual vaccination with injectable influenza vaccines may interfere with the development of broad immunity against influenza that could otherwise be induced by natural infection [11]. Vaccination-related effects sometimes exacerbate viral infections (e.g., respiratory syncytial virus; dengue virus; measles virus; influenza virus) [12-14]. The consequence of a vaccination-induced polarized T-cell memory profile on clinical outcomes is largely a terra incognita $[15,16]$. Improper injection of vaccines into the arm can provoke an inflammation that damages tendons, ligaments, bursas and reduce friction in the joint $[7,17]$. For every vaccine that causes a tangible injury, there may be many more vaccines that cause either minor injuries or major injuries in a slow motion, as suggested by the Heinrich's law. Even one injury from vaccination is one too many. It is thus counterfactual to assert that vaccination is universally safe with only minor risks. These lines of evidence complicate the picture of vaccine safety as the obscure findings lend weight to the risk of missing vaccines' real McCoy - "keep people healthy." To date, there has been little to no discussion of how these revelations may guide policies on vaccine safety, which is intrinsic to the vaccine industry, coursing through anti-vaccine movement, and prevalent in society at large.

Overall, the weight of evidence suggests that systemic inflammation and possibly other reactions induced by i.m. vaccination may not be medically benign with the possibility to pose unwarranted health threats to vaccinees who are otherwise healthy. The only redemption from them is to rise above paradigms for revealing the underlying mechanisms in conjunction with the development of novel vaccines that are integrated to steering vaccination away from self-destruction toward protection in order to durably prevent collateral damage with a positive benefit:risk profile.

\section{Systemic inflammation as an arcane leviathan with the potential to anchor system-wide mayhem following in- tramuscular vaccination}

Intramuscular injection with a hypodermic syringe needle is an age-old medical practice that has been dominating the vaccination skyline as the principal modality for the delivery of vaccines. However, this invasive mode invariably induces a systemic burst of overly exuberant inflammation in nearly all vaccinees shortly post-injection. The big question is whether this biological paradox could resolve itself over time. Evidence shows that acute inflammation may be discreetly abated to chronic inflammation with dicey consequences among at least a subset of vaccinees, along with a variety of measurable symptoms including pain, headache, fatigue, and fever (Table 1) $[18,19]$. Most of the side effects induced by licensed vaccines are seemingly local with short duration; however, World Health Organization (WHO) Global Advisory Committee on Vaccine Safety released a precaution that only a subset of the vaccination-induced adverse events could be identified with today's technology [18]. Moreover, the National Vaccine Injury Compensation Program (VICP) was launched in the U.S. for victims injured by vaccines to win damages from a government trust fund [7].

Inflammatory cytokines are the principal driver for eliciting both protective immunity and adverse inflammatory events. Systemic inflammation is one of the consequences after massive release of proinflammatory molecules into the circulatory system [20]. Although inflammation could enable the host to rapidly fend off a subset of disease-causing agents, systemic inflammation accentuates in multiple forms that vary with the state of health as well as immune profile. Investigations have uncovered a discomfiting reality by implicating systemic inflammation as a risk factor in the etiology of a wide range of disease states. Injection of an adjuvanted vaccine usually induces acute inflammation within hours. Resolution of inflammation requires synchronization of complex reactions with its precise mechanisms only partially revealed [20]. Failure to coordinate comorbid reactions tightly during the healing process could culminate in chronic inflammation and tissue injury, which unfortunately occur. Most vaccinees, including vaccine supporters, only semiconsciously consent to vaccines' risks without knowing the possibility for acute inflammation to discreetly evolve into chronic low-grade inflammation with a heightened risk [18].

Chronic low-grade inflammation as a medical concept had been a nebulous villain until evidence articulately showed that this seemingly inconsequential state actually contributes to the pathophysiology of an array of infirmities. Chronic inflammatory diseases represent complex and insidious disorders involving a multitude of pathogenic reactions collectively mediate an indelible disease state. Vaccination-induced 
chronic inflammation may develop when acute inflammation is not resolved post-immunization due to the type of vaccines, environmental factors, genetic predispositions, health statuses, immune profiles, and/or matters of chance. The outcomes depend on where the runaway reaction takes hold within a vaccinee. Just because chronic inflammation exists silently does not make it less hazardous than acute inflammation although the former is difficult to measure and hard to comprehend. Medical evidence has already depicted compelling links between chronic low-grade inflammation and a variety of health infirmities including cardiovascular disease, obesity, diabetes, cancer, and neurological disorder on an expanding horizon [18,21,22].

Even ephemeral systemic inflammation induced by i.m. injection of an influenza vaccine is associated with temporary deterioration of cardiac autonomic nervous system, as well as abnormalities in arterial function and low-density lipoprotein (LDL) oxidation, which may contribute, in part, to the reported increase in cardiovascular risk during the first weeks post-vaccination. This invasive regimen is also linked to low risks for Guillain-Barré syndrome and narcolepsy (Table 1) [18]. In addition to influenza vaccines, i.m. injection of the Salmonella typhi vaccine impairs endothelium-dependent vasodilation within hours in healthy young individuals, suggesting an adverse effect on the vasculature [18]. Typhoid polysaccharide vaccine injection produced a robust inflammatory response indexed by increased circulating interleukin (IL)- 6 accompanied by a significant increase in fatigue, confusion, and impaired concentration [23], along with disrupted sleep cycles [24]. Vaccinees experienced a cellulitis-like reaction, fever, and leukocytosis in the days following injection of a pneumococcal polysaccharide vaccine [25]. All of the widely administered vaccines are associated with uveitis with the $\mathrm{HBV}$ vaccine as the leading offender [26] (Table 1).

Vaccines commonly contain adjuvants [e.g., aluminum compound (alum)] which prod immune and inflammatory responses. Intramuscular injection of alum-containing vaccines often induces macrophagic myofasciitis lesions, showing long-term persistence of alum as well as sustained immune reactions within vaccinees for many years post-injection $[27,28]$. There are clues that chronic adjuvant stimulation which induces a state of prolonged immune activation may tip the immune scale toward predisposition of a lymphoma state [29]. Alum adjuvant has been implicated in exacerbating vaccinationinduced inflammation by modulating multiple immune cells toward collateral damage of host tissues [30]. Alum activates the inflammasome at least in part, in causing a Muckle-Wells syndrome-like effect which is manifested as fever, myalgia, lethargy, and chronic inflammation to varying degrees among vaccinees [18] (Table 1). Vaccinemakers' claim that the trace amount of alum blended into a vaccine is harmless thus has to be reexamined from a chronic angle during multiple cycles of vaccination over a lifetime.

An array of inflammatory biomarkers [e.g., granulocytes; C-reactive protein (CRP); tumor necrosis factor (TNF)- $\alpha$; IL-6] have been analyzed in order to quantitatively measure the degree of systemic inflammation. The concomitant changes of CRP levels and heart rate variability parameters following i.m. injection of an influenza vaccine suggested a pathophysiological link between vaccination-induced subclinical inflammatory state and impaired cardiac parasympathetic function, which may increase the risk of cardiovascular events. Significant increases in granulocytes, CRP, TNF- $\alpha$, and/or IL-6 levels were observed in vaccinees shortly after i.m. injection of HBV, influenza, or Salmonella typhi vaccines [18,31] (Table 1). Evidence shows that IL- 6 may impair Th1 differentiation and attenuate responses of $\mathrm{CD}^{+}$effector $\mathrm{T}$ cells [32].
Inflammatory signaling and its resolution pathways remain largely enigmatic, with evidence implicating the prostaglandin E2EP4-IL-22 axis as one of the arms that control the degree of systemic inflammation [20]. Since early-life chronic inflammation is linked with later morbidity [33] and vaccination induces inflammation, these converging perspectives create a logistical caveat: If vaccinationinduced systemic inflammation should drive any chronic infirmity, this common medical regimen may discreetly sicken vaccinees who are otherwise healthy in a slow motion. Overall, we will be sorely misguided and miss a theme unifying divergent adverse effects if we deem vaccination-induced side effects are manifested as unimodal symptoms shortly post-vaccination. Should systemic inflammation be the locomotive of health infirmities, disease states may manifest as cabooses with seemingly unrelated symptoms in myriad ways. Vaccination-induced systemic inflammation thus could represent a biological linchpin around which health threats revolve carrying an incalculable price. Although the science is still inconclusive in support of a prognostication declaring inflammation in temporal association with vaccination as the root cause in chronic disease settings, it is of paramount urgency to unravel the intricate pas de deux between vaccination and inflammation over a lifetime. As our understanding of how vaccination-induced systemic inflammation and its complications enlarge, so will the potential repertoire of medical intervention for bringing vaccination-associated side effects to a sensible and humane solution.

\section{Noninvasive vaccination as a juggernaut to minimize vaccination-induced systemic inflammation}

Systemic inflammation and its associated adverse effects described above are induced by i.m. vaccination in an invasive mode (Tables 1 and 2). From a logistic point of view, it is risky to inject vaccines into muscle because the immune system conceivably would be surprised by exogenous antigens found in deep tissues where a rendezvous with pathogen is a rare event. Per Darwinian evolution, the immune system ought to be more competent along the periphery since protection of a host against pathogens at the portal sites without inducing prolonged systemic inflammation is vital for survival (Table 2). To date, development of noninvasive vaccines has opened up a new front by atraumatic delivery of vaccines to the outer layer of tissues along the interface (digestive tract; respiratory tract; skin) in a simple, effective, painless, economical and safe manner. Since the mucocutaneous barrier is in constant contact with a myriad of commensal microbes and innocuous antigens, the periphery immune system is required to perform an arduous duty by playing dual roles on diametrically opposed mechanisms between protective immunity and immune tolerance. Emerging evidence has shown that the periphery immune system is

Table 2. Injectable vaccines versus noninvasive vaccines

\begin{tabular}{|l|l|l|}
\hline & $\begin{array}{l}\text { Injectable } \\
\text { vaccines }\end{array}$ & $\begin{array}{l}\text { Noninvasive vaccines (oral, } \\
\text { nasal, skin-patch vaccines) }\end{array}$ \\
\hline Mode of delivery & $\begin{array}{l}\text { Invasive and } \\
\text { traumatic }\end{array}$ & Noninvasive and atraumatic \\
\hline Pain and fear & Yes & No \\
\hline Local inflammation & Yes & Yes \\
\hline Systemic inflammation & Yes & None or mild \\
\hline Adverse side effects & Myriad & Limited and mild \\
\hline Resolution of inflammation & Slow & Rapid \\
\hline Medical skill required & High & Low \\
\hline Self-vaccination during a crisis & Undoable & Doable \\
\hline $\begin{array}{l}\text { Self-booster application to fortify } \\
\text { protective immunity }\end{array}$ & Undoable & Doable \\
\hline
\end{tabular}


indeed more competent than its deep-tissue counterpart in restraining inflammation in order not to mistakenly summon a detrimental immune overdrive during daily encounter with environmental microbes $[18,34,35]$.

Oral, nasal, and skin-patch vaccines have been developed to elicit protective immunity by noninvasive delivery of vaccines to the mucocutaneous interface. Although oral vaccines against polio and cholera have been deployed with varying degrees of success [18], progress to develop oral vaccines is limited owing to multiple obstacles including interference from food particles and gut microbiome, enzymatic digestion of antigens, inefficient antigen delivery across epithelial cells into mucosa-associated lymphoid tissue (MALT) in the gastrointestinal (GI) tract, enteropathy found in developing countries $[36,37]$, as well as the oral mucosal immune system which tends to induce tolerance upon exposure to dietary antigens that trigger the generation of retinoid-related orphan receptor gamma $t(\mathrm{ROR} \gamma \mathrm{t})$ deficient regulatory $\mathrm{T}$ cells in the GI tract [38]. The demonstration that oral vaccines' efficacy could be improved by targeting intestinal microfold (M) cells with biodegradable microparticles [39] or feeding vaccinees with a buffer solution in advance [40] offers hope for enhancing the potency of oral vaccines. Reversion and spread of vaccine-derived poliovirus (VDPV) to cause outbreaks of poliomyelitis is a rare outcome resulting from immunization with the live-attenuated oral poliovirus vaccines (OPVs) [41], which could be circumvented by the development of vectored vaccines [42] or premature termination codon (PTC)-harboring virus vaccines [43]. Alternatively, protective immunity within the GI tract can be elicited by a nasal vaccine, which may be superior to its oral counterpart in eliciting protective immunity against oral pathogens since vaccination at one mucosal site induces immunity at peripheral mucosal sites via the common mucosal immune system and the pulmonary mucosal immune system appears to be more immunocompetent than its GI counterpart [18].

A licensed nasal influenza vaccine formulated with cold-adapted live-attenuated influenza virus (LAIV; known as FluMist in the U.S.) has been deployed for mass-immunization by nasal spray, which has proven safe with equivalent or superior efficacy against influenza compared with systemic i.m. vaccination [44] (at least during some of the years) although the LAIV-induced serum antibody titer is consistently low $[45,46]$. In contrast to i.m. vaccination, nasal spray of LAIV induces neither systemic inflammation [34,46] nor vaccineassociated enhanced respiratory disease [47]. Since LAIV-induced seroconversion rate is inversely correlated with pre-existing levels of granulocyte colony-stimulating factor (G-CSF) which is associated with recruitment of neutrophils [34], it is hypothesized that phagocytosis along the mucosal barrier may restrict LAIV dissemination, allowing nasal vaccines to focus on antigen presentation at mucosal sites with diminished potential to induce systemic inflammation by preventing LAIV from entering circulation. Mechanistically, antigen presentation and immune memory do not require absorption of nasal vaccines into circulation because pulmonary defenses may be bolstered by transient assembly of tertiary lymphoid structures post-vaccination in the lungs $[48,49]$, and memory $\mathrm{T}$ cells in mice and humans could be generated and maintained in compartmentalized niches within lungs [50], independent of secondary lymphoid organs. The hazard of systemic inflammation thus could be appreciably reduced when injectable vaccines are substituted by nasal vaccines, or other noninvasive vaccines (Table 2).

Emerging evidence suggested that it may be a common event for a small number of viral particles to enter the brain through the olfactory tract [51,52], although the defense mechanism within an immunocompetent brain conceivably would arrest the virus before it replicates out of control. The safety profile of LAIV [45] corroborates the hypothesis that the influenza virus-induced encephalitis [53] could be attributed to viral replication in the brain since LAIV can only replicate for limited cycles in the airway where temperature is lower but not within the brain where it is too hot. Nasal vaccination with non-replicating viruses or bioengineered vectors in compliance with evolutionary medicine [54] thus represents a driver in the pursuit of vaccine safety.

A skin-patch vaccine mobilizes the immune repertoire in an altogether different way than vaccines that preceded it. Ironically, this trail was initially blazed by the development of a penetrating device - the gene gun designed for the delivery of DNA vaccines into skin [55]. Subsequent evidence showed that the depth of DNA penetration is inversely correlated with its potency; i.e., the deeper, the weaker. The optimal mode for the delivery of DNA vaccine is thus to gently inoculate DNA into the outermost layer of epidermis where a rendezvous with pathogen is so everyday [56]. This contrarian finding marks the debut of noninvasive skin vaccination. Since the outermost layer of epidermis can be easily targeted without the requirement for using a penetrating device, the development of a noninvasive skin-patch vaccine would be a logical next step. To date, the skin-patch vaccine delivered by topical application onto unbroken skin [35,57-60] represents a nifty class of noninvasive vaccines with the potential to confer protection against pathogens in conjunction with rapid resolution of vaccination-induced inflammation. In stark contrast to the overt skin irritation following intradermal injection of vaccines, immunization by topical application of a vaccine patch is far more benign [35].

Since the cells along the mucocutaneous interface are essentially disposable in an orderly fashion with the outer layer constantly replenished with new cells, limited local inflammation induced by noninvasive vaccination along the superficial layer of tissues would have little adverse impact on overall health in contrast to systemic inflammation which simmers internal organs. There are thus compelling reasons to transform vaccinology on the cusp of a paradigm shift to an infallible formula which brings the noninvasive-vaccine bellwether to a clear focus for achieving safe immunization by quelling systemic inflammation in many mucocutaneous disease settings.

\section{Vaccinal math}

Contemporary vaccines are largely administered invasively by needle injection which represents a necessary evil that vaccinees love to hate. From an evolutionary point of view, needle injection, or penetration by a foreign object universally perpetuates the fear factor among all animals including humans. Transformation of injectable vaccine to its noninvasive counterpart which induces neither pain nor fear should be a palliative to address the deep anxieties associated with needle injection with the potential to presciently boost vaccine coverages worldwide.

Administration of vaccines by needle injection demands medical expertise backed up by licensed medical personnel in the modern health care system which is in short supply among developing countries. In contrast, noninvasive vaccination could be performed by personnel with a low level of training. Hence mass-immunization with noninvasive vaccines is an expedient way to liberate precious medical resources which can subsequently be re-focused to support other urgent medical needs. 
It is inconveniently true that i.m. vaccination induces systemic inflammation, which may slowly confer cumulative deleterious effects with the potential to reach a crisis level over time. Although it is still inconclusive whether systemic inflammation induced by i.m. vaccination is a culprit for driving myriad diseases in humans, tampering with the natural setting by surprising the immune system with needle injection is inherently risky since it may induce unforeseeable perils. Bottom line: Public health cannot be left to chance by gaming uncertainty. It is thus reason enough to develop noninvasive vaccines that do not induce systemic inflammation as the clues are abundantly clear that systemic inflammation is an existential threat that has to be avoided, if avoidable. In case i.m. vaccinationinduced systemic inflammation should wreak health havoc by allowing chronic infirmities to fester under the medical radar, transformation of injectable vaccine to its noninvasive counterpart would be a medically and economically sound approach to prevent the ravages of systemic inflammation.

Overall, contemporary i.m. vaccination is Pyrrhic when antivaccine sentiment, fear of injection, medical training, and systemic inflammation are factored in (Table 2). Noninvasive vaccination stands to upend the obstacles associated with i.m. vaccination. The propitious time may have come to create an inflection point by widely replacing injectable vaccines with noninvasive oral, nasal and skin-patch vaccines against mucocutaneous pathogens. This pro-noninvasiveness movement would change public health policies disruptively by saving time, minimizing inconvenience, reducing cost, and eliminating fear; it would measurably mitigate vaccination-induced systemic inflammation; it would productively build a campaign that could coalesce the anti-vaccine movements by effectively harnessing their energy on a win-win track; and it may lead to injectable vaccines increasingly sunsetting into an anachronism during the never-ending war against mucocutaneous pathogens.

\section{Conclusion}

Vaccination can be a costly imposition; and like tobacco smoking, its health threat is not immediately obvious. Although vaccination has proven effective in boosting public health by preventing a wide range of diseases, i.m. vaccination is no longer sacrosanct as it has courted controversy in the context of opprobrium from anti-vaccine movements. With major strides in understanding how systemic inflammation impacts health, it is nearly impossible to provide full assurance of safety for injectable vaccines since i.m. vaccination invariably induces systemic inflammation which is associated with a multitude of adverse events with inter-subject variation owing to genetic polymorphisms underpinning the broad spectrum of responsiveness and scale of protection versus inflammation within a vaccinated population [61]. The myriad manifestations and the incertitude of mechanisms surrounding the vaccination-inflammation axis collectively present a dilemma with deep policy implications. On logical grounds and sound evidence, the way to promote vaccine coverages on the basis of safety is to promote noninvasive vaccines on the basis of safety, since noninvasive vaccination could spare vaccinees the health-sapping effects of systemic inflammation. Once noninvasive vaccination has built enough momentum propelled by demonstrable medical reasons, the development conceivably could generate a lofty trend by triggering wholesale changes for lifting mass-vaccination to boffo heights. It is thus auspicious to forecast an armistice between pro- and antivaccine groups by including the entire human race as the sole beneficiary.

Injectable vaccine, regardless of its propensity to undermine the safety of public health by inducing systemic inflammation, will continue to thrive in perpetuity as an indispensable medical tool since systemic immunity elicited by i.m. vaccination is essential for conferring protection against cancer as well as a range of internal pathogens (e.g., $\mathrm{HBV}$; malaria protozoan; dengue virus). However, it is conceivable that the degree of vaccination-induced systemic inflammation could be greatly reduced by including noninvasive vaccination as a component in conjunction with i.m. vaccination in a heterologous prime-boost regimen $[62,63]$, which tends to elicit immune responses of greater height and breadth than can be achieved by homologous prime-boost when the same vaccine is repeatedly injected [64]. The leap to a new global vaccination program which includes noninvasive vaccination as one of the arms could appear as a game changer with the potential to upend the entire vaccine industry. If noninvasive vaccines are safe enough, effective enough, and economical enough, they will emerge as the de facto standard against mucocutaneous pathogens or against other diseases in conjunction with i.m. vaccination in a heterologous prime-boost strategy.

\section{Acknowledgments}

DC Tang is a recipient of grants from the NIH (USA) and the TMMU (China).

\section{References}

1. Spier RE (2001) Perception of risk of vaccine adverse events: a historical perspective Vaccine 20 Suppl 1: S78-84. [Crossref]

2. Dube E, Vivion M, MacDonald NE (2015) Vaccine hesitancy, vaccine refusal and the anti-vaccine movement: influence, impact and implications. Expert Rev Vaccines 14:99-117. [Crossref]

3. McNutt LA, Desemone C, DeNicola E, El Chebib H, Nadeau JA, et al. (2016) Affluence as a predictor of vaccine refusal and underimmunization in California private kindergartens. Vaccine 34: 1733-1738. [Crossref]

4. Yang YT, Delamater PL, Leslie TF, Mello MM (2016) Sociodemographic predictors of vaccination exemptions on the basis of personal belief in California. Am J Public Health 106:172-177. [Crossref]

5. Salmon DA, Dudley MZ, Glanz JM, Omer SB (2015) Vaccine hesitancy: Causes, consequences, and a call to action. Vaccine 4: D66-71. [Crossref]

6. Wadman M, You J (2017) The vaccine wars. Science 356: 364-365. [Crossref]

7. Wadman M (2017) Vaccines on trial. Science 356: 370-373. [Crossref]

8. Goldman GS, Miller NZ (2012) Relative trends in hospitalizations and mortality among infants by the number of vaccine doses and age, based on the Vaccine Adverse Even Reporting System (VAERS), 1990-2010. Hum Exp Toxicol 31:1012-1021. [Crossref]

9. Klein NP, Lewis E, Fireman B, Hambidge SJ, Naleway A, et al. (2015) Safety of measlescontaining vaccines in 1-year-old children. Pediatrics 135: e321-329. [Crossref]

10. Nakayama T, Kumagai T, Nishimura N, Ozaki T, Okafuji T, et al. (2015) Seasonal split influenza vaccine induced IgE sensitization against influenza vaccine. Vaccine 33: 6099-6105. [Crossref]

11. Bodewes R, Fraaij PL, Kreijtz JH, Geelhoed-Mieras MM, Fouchier RA, et al. (2012) Annual influenza vaccination affects the development of heterosubtypic immunity. Vaccine 30:7407-7410. [Crossref]

12. Ubol S, Halstead SB (2010) How innate immune mechanisms contribute to antibodyenhanced viral infections. Clin Vaccine Immunol 17: 1829-1835. [Crossref]

13. Khurana S, Loving CL, Manischewitz J, King LR, Gauger PC, et al. (2013) Vaccineinduced anti-HA2 antibodies promote virus fusion and enhance influenza virus respiratory disease. Sci Transl Med 5: 200ra114.

14. To KK, Zhang AJ, Hung IF, Xu T, Ip WC, et al. (2012) High titer and avidity of nonneutralizing antibodies against influenza vaccine antigen are associated with severe influenza. Clin Vaccine Immunol 19:1012-1018. [Crossref]

15. White OJ, Rowe J, Richmond P, Marshall H, McIntyre P, et al. (2010) Th2-polarisation of cellular immune memory to neonatal pertussis vaccination. Vaccine 28: 2648-2652. [Crossref]

16. Madura Larsen J, Benn CS, Fillie Y, van der Kleij D, Aaby P, et al. (2007) BCG stimulated dendritic cells induce an interleukin-10 producing T-cell population with no T helper 1 or T helper 2 bias in vitro. Immunology 121: 276-282. [Crossref] 
17. Martín Arias LH, Sanz Fadrique R, Sáinz Gil M, Salgueiro-Vazquez ME (2017) Risk of bursitis and other injuries and dysfunctions of the shoulder following vaccinations. Vaccine S0264-410X: 30963-30965. [Crossref]

18. Tang DC, Nguyen HH (2014) The Yin-Yang arms of vaccines: disease-fighting power versus tissue-destructive inflammation. Expert Rev Vaccines 13: 417-427. [Crossref]

19. Andersen T (2016) WHO approves world's first ever dengue vaccine. TIME.

20. Duffin R, O'Connor RA, Crittenden S, Forster T, Yu C, et al. (2016) Prostaglandin E, constrains systemic inflammation through an innate lymphoid cell-IL-22 axis. Science 351: 1333-1338. [Crossref]

21. Harrison NA, Cooper E, Dowell NG, Keramida G, Voon V, et al. (2015) Quantitative magnetization transfer imaging as a biomarker for effects of systemic inflammation on the brain. Biol Psychiatry 78:49-57. [Crossref]

22. Heneka MT, Carson MJ, El Khoury J, Landreth GE, Brosseron F, et al. (2015) Neuroinflammation in Alzheimer's disease. Lancet Neurol 14: 388-405. [Crossref]

23. Harrison NA, Brydon L, Walker C, Gray MA, Steptoe A, et al. (2009) Neural origins of human sickness in interoceptive responses to inflammation. Biol Psychiatry 66: 415422. [Crossref]

24. Sharpley AL, Cooper CM, Williams C, Godlewska BR, Cowen PJ, et al. (2016) Effects of typhoid vaccine on inflammation and sleep in healthy participants: a double-blind, placebocontrolled, crossover study. Psychopharmacology (Berl) 233: 3429-3435. [Crossref]

25. von Elten KA, Duran LL, Banks TA, Banks TA, Collins LC, et al. (2014) Systemic inflammatory reaction after pneumococcal vaccine: a case series. Hum Vaccin Immunother 10:1767-1770. [Crossref]

26. Benage M, Fraunfelder FW (2016) Vaccine-associated uveitis. Mo Med 113: 48-52. [Crossref]

27. Gherardi RK, Coquet M, Cherin P, Belec L, Moretto P, et al. (2001) Macrophagic myofasciitis lesions assess long-term persistence of vaccine-derived aluminium hydroxide in muscle. Brain 124:1821-1831. [Crossref]

28. Gherardi RK, Authier FJ (2012) Macrophagic myofasciitis: characterization and pathophysiology. Lupus 21: 184-189. [Crossref]

29. Butnaru D, Shoenfeld Y (2015) Adjuvants and lymphoma risk as part of the ASIA spectrum. Immunol Res 61: 79-89. [Crossref]

30. Kim KH, Lee YT, Hwang HS, Kwon YM, Jung YJ, et al. (2015) Alum adjuvant enhances protection against respiratory syncytial virus but exacerbates pulmonary inflammation by modulating multiple innate and adaptive immune cells. PLOS ONE 10:e139916. [Crossref]

31. McDade TW, Borja JB, Kuzawa CW, Perez TL, Adair LS (2015) C-reactive protein response to influenza vaccination as a model of mild inflammatory stimulation in the Philippines. Vaccine 33:2004-2008. [Crossref]

32. Tsukamoto H, Senju S, Matsumura K, Swain SL, Nishimura Y (2015) IL-6-mediated environmental conditioning of defective Th1 differentiation dampens antitumour immune responses in old age. Nat Commun 6:doi: 10.1038/ncomms7702. [Crossref]

33. Finch CE, Crimmins EM (2004) Inflammatory exposure and historical changes in human life-spans. Science 305: 1736-1739. [Crossref]

34. Barría MI, Garrido JL, Stein C, Scher E, Ge Y, et al. (2013) Localized mucosal response to intranasal live attenuated influenza vaccine in adults. J Infect Dis 207:115124. [Crossref]

35. Wang J, Li B, Wu MX (2015) Effective and lesion-free cutaneous influenza vaccination. Proc Natl Acad Sci U S A 112: 5005-5010. [Crossref]

36. Watanabe K, Petri WAJ (2016) Environmental enteropathy: elusive but significant subclinical abnormalities in developing countries. EBioMedicine 10:25-32. [Crossref]

37. Rogawski ET, Guerrant RL (2017) The burden of enteropathy and "subclinical" infections. Pediatr Clin North Am 64: 815-836. [Crossref]

38. Kim KS, Hong SW, Han D, Yi J, Jung J, et al. (2016) Dietary antigens limit mucosal immunity by inducing regulatory T cells in the small intestine. Science 351:858-863. [Crossref]

39. Tawde SA, Chablani L, Akalkotkar A, D'Souza C, Chiriva-Internati M, et al. (2012) Formulation and evaluation of oral microparticulate ovarian cancer vaccines. Vaccine 30:5675-5681. [Crossref]

40. Zeng M, Mao XH, Li JX, Tong WD, Wang B, et al. (2015) Efficacy, safety, and immunogenicity of an oral recombinant Helicobacter pylori vaccine in children in China: a randomised, double-blind, placebo-controlled, phase 3 trial. Lancet 386:14571464. [Crossref]

41. Pons-Salort M, Burns CC, Lyons H, Blake IM, Jafari H, et al. (2016) Preventing vaccine-derived poliovirus emergence during the polio endgame. PLoS Pathog 12:e1005728. [Crossref]
42. Zhang J, Tarbet EB, Toro H, Tang DC (2011) Adenovirus-vectored drug-vaccine duo as a potential driver for conferring mass-protection against infectious diseases. Expert Rev Vaccines 10:1539-1552. [Crossref]

43. Si L, Xu H, Zhou X, Zhang Z, Tian Z, et al. (2016) Generation of influenza A viruses as live but replication-incompetent virus vaccines. Science 354: 1170-1173. [Crossref]

44. Rose MA (2014) Mucosal immunization in perspective. Hum Vaccin Immunother 10: 2115-2117. [Crossref]

45. Carter NJ, Curran MP (2011) Live attenuated influenza vaccine (FluMist ${ }^{\mathbb{E}}$; Fluenz ${ }^{\mathrm{TM}}$ ): a review of its use in the prevention of seasonal influenza in children and adults. Drugs 71:1591-1622. [Crossref]

46. Ramakrishnan A, Althoff KN, Lopez JA, Coles CL, Bream JH (2012) Differentia serum cytokine responses to inactivated and live attenuated seasonal influenza vaccines. Cytokine 60: 661-666. [Crossref]

47. Gauger PC, Loving CL, Khurana S, Lorusso A, Perez DR, et al. (2014) Live attenuated influenza A virus vaccine protects against A(H1N1)pdm09 heterologous challenge without vaccine associated enhanced respiratory disease. Virology 471-473:93-104. [Crossref]

48. Leslie M (2016) Immunity goes local. Science 352: 21-23. [Crossref]

49. Yadava K, Bollyky P, Lawson MA (2016) The formation and function of tertiary lymphoid follicles in chronic pulmonary inflammation. Immunology 149: 262-269. [Crossref]

50. Turner DL, Bickham KL, Thome JJ, Kim CY, D'Ovidio F, et al. (2014) Lung niches for the generation and maintenance of tissue-resident memory T cells. Mucosal Immunol 7: 501-510. [Crossref]

51. Zhang SY, Jouanguy E, Ugolini S, Smahi A, Elain G, et al. (2007) TLR3 deficiency in patients with herpes simplex encephalitis. Science 317: 1522-1527. [Crossref]

52. Underwood E (2017) The polluted brain. Science 355: 342-345. [Crossref]

53. Toovey S (2008) Influenza-associated central nervous system dysfunction: a literature review. Travel Med Infect Dis 6:114-124. [Crossref]

54. Tang DC, Van Kampen KR (2008) Toward the development of vectored vaccines in compliance with evolutionary medicine. Expert Rev Vaccines 7: 399-402. [Crossref]

55. Tang DC, DeVit M, Johnston SA (1992) Genetic immunization is a simple method for eliciting an immune response. Nature 356: 152-154. [Crossref]

56. Tang DC (2014) A trail blazed through DNA vaccine, noninvasive vaccine, and innateadaptive immunity duo. Hum Vaccin Immunother 10: 2143-2146. [Crossref]

57. Tang DC, Shi Z, Curiel DT (1997) Vaccination onto bare skin. Nature 388: 729-730. [Crossref]

58. Glenn GM, Rao M, Matyas GR, Alving CR (1998) Skin immunization made possible by cholera toxin. Nature 391: 851. [Crossref]

59. Glenn GM, Taylor DN, Li X, Frankel S, Montemarano A, et al. (2000) Transcutaneous immunization: A human vaccine delivery strategy using a patch. Nat Med 6:1403-1406. [Crossref]

60. Zhang J, Shi Z, Kong FK, Jex E, Huang Z, et al. (2006) Topical application of Escherichia coli-vectored vaccine as a simple method for eliciting protective immunity. Infect Immun 74:3607-3617. [Crossref]

61. Li Y, Oosting M, Deelen P, Ricaño-Ponce I, Smeekens S, et al. (2016) Inter-individual variability and genetic influences on cytokine responses to bacteria and fungi. Nat Med 22: $952-960$.

62. Khurana S, Coyle EM, Manischewitz J, King LR, Ishioka G, et al. (2015) Oral priming with replicating adenovirus serotype 4 followed by subunit H5N1 vaccine boost promotes antibody affinity maturation and expands $\mathrm{H} 5 \mathrm{~N} 1$ cross-clade neutralization. PLOS ONE 10: e0115476. [Crossref]

63. Obaldia Nr, Stockelman MG, Otero W, Cockrill JA, Ganeshan H, et al. (2017) A Plasmodium vivax plasmid DNA- and adenovirus-vectored malaria vaccine encoding blood stage antigens AMA1 and MSP142 in a prime/boost heterologous immunization regimen partially protects Aotus monkeys against blood stage challenge. Clin Vaccine Immunol 24: e00539-00516. [Crossref]

64. Kardani K, Bolhassani A, Shahbazi S (2016) Prime-boost vaccine strategy against viral infections: Mechanisms and benefits. Vaccine 34: 413-423. [Crossref]

Copyright: (C2017 Tang DC. This is an open-access article distributed under the terms of the Creative Commons Attribution License, which permits unrestricted use, distribution, and reproduction in any medium, provided the original author and source are credited. 